\title{
Surgical resection of resectable thoracic metastatic hepatocellular carcinoma after liver transplantation
}

\author{
Chong Zhang, MD, Jian Rao, MD, Zhengliang Tu, MD, and Yiming Ni, MD, Hangzhou, China
}

Although the role of orthotopic liver transplantation (OLT) in the treatment of hepatocellular carcinoma (HCC) has improved over the years, tumor recurrence is still a major imitation of long-term survival even after radical transplantation treatment. ${ }^{1}$ Thoracic metastasis is the most common site of extrahepatic spreads. The role of surgery for thoracic metastasis is not known, and until now there have been few reports about surgical resection for thoracic HCC metastasis after liver transplantation. We evaluate the surgical efficacy in the treatment of thoracic HCC recurrence after OLT.

\section{CLINICAL SUMMARY}

Between October of 2003 and September of 2007, 5 patients who had undergone OLT for HCC demonstrated resectable thoracic $\mathrm{HCC}$ recurrence and were admitted to the Department of Thoracic and Cardiovascular Surgery without other identifiable recurrence foci. Thoracic recurrence was located in the right lower lobe and the upper lobe in 1 patient, the right lower lobe in 1 patient, the fourth to sixth right costal cartilage and the right lower lobe in 1 patient, the middle lobe in 1 patient, and the right upper lobe in 1 patient. They underwent standard lobectomy or wedge resection for thoracic recurrence. The specimen pathology showed all low differentiated metastatic HCC, except a benign nodule of the right lower lobe in the patient with recurrence in the costal cartilage. After surgical resection, no patient received chemotherapy or other adjuvant treatments. Patients were followed up at interval with laboratory analysis and whole body scan for physical conditions and a second recurrence. HCC recurrence developed in the left adrenal gland in 1 patient 6 months after right lower lobectomy. Left adrenal gland resection was performed under laparoscopic surgery, and the pathology revealed low differentiated metastatic HCC. The other 4 patients have no recurrence, and all 5 patients are currently alive. The time from transplant to diagnosis of thoracic recurrence ranged from 8 to 33 months, with an average period of 18.6 months. The survival time from transplant ranged from 16 to 85 months, with a mean time of 37.4 months. The survival time from thoracic resection ranged from 3 to 53 months, with an average time of 17.8 months.

\footnotetext{
From the Department of Thoracic and Cardiovascular Surgery, The First Affiliated Hospital, College of Medicine, Zhejiang University, Hangzhou, China. Received for publication Feb 23, 2008; accepted for publication May 4, 2008

Address for reprints: Yiming Ni, MD, Department of Thoracic and Cardiovascular

Surgery, The First Affiliated Hospital, College of Medicine, Zhejiang University,

Hangzhou 310003, China (E-mail: haiyanzhangchong@163.com).

J Thorac Cardiovasc Surg 2009;138:240-1

$0022-5223 / \$ 36.00$

Copyright (c) 2009 by The American Association for Thoracic Surgery doi: $10.1016 /$ j.jtcvs.2008.05.014
}

The study was retrospective and approved by all 5 patients. All thoracic surgical management, survival time, and other clinical parameters are reviewed in Table 1.

\section{DISCUSSION}

Liver transplantation was considered as radical surgery macroscopically (the tumor is resected completely and there is no residual tumor tissue from surgeon's eye and radiography) for patients with HCC. However, tumor recurrence was the major limitation of long-term survival after liver transplantation. Although intrahepatic recurrence predominated, the most common location of extrahepatic metastasis was the thorax. ${ }^{2}$ Survival for patients with recurrence was significantly shorter than for patients undergoing transplantation for HCC without recurrence. Thoracic recurrence was mainly detected by biochemical and radiographic evidence. Increased alpha-fetoprotein level was generally an early key indicator for any advanced radiographic evidence of HCC recurrence. Enhanced computed tomography, ultrasonography, positron emission tomography, and radionuclide bone imaging were also important as routine initial or advanced screening for recurrence evidence.

Although some studies have shown that only adjuvant treatments for posttransplant HCC recurrence without surgical resection may be good to increase survival, a better benefit may be obtained from metastasectomy. ${ }^{3}$ The type of surgical resection was based on the patients' anatomic and physiologic considerations. Radical lobectomy was preferred, and wedge resection was considered according to the recurrence anatomic site, numbers, pulmonary function, and even the request of the patients. All 5 patients are currently alive, and the average survival time from thoracic resection is 17.8 months, which is similar to the results of previous reports. ${ }^{3}$ Although the size of our study population was small, the survival time in these patients is encouraging. A larger study may be necessary to assess the possible benefits of surgical resection and surgical types for resectable thoracic metastasis after liver transplantation for $\mathrm{HCC}$. These aims should be accomplished with advanced investigation in a larger population and a longer follow-up for similar patients.

\section{CONCLUSIONS}

There have been few reports about surgical resection for thoracic metastasis after liver transplantation for HCC. In our series, metastasectomy for resectable thoracic HCC recurrence after liver transplantation was encouraging and is suggested as a reasonable treatment. 
TABLE 1. Characteristics of patients and data of recurrence, metastasectomy, survival time

\begin{tabular}{|c|c|c|c|c|c|}
\hline Patient & 1 & 2 & 3 & 4 & 5 \\
\hline Gender & Male & Male & Male & Male & Male \\
\hline Age, y & 49 & 66 & 47 & 63 & 37 \\
\hline \multicolumn{6}{|l|}{ Thoracic recurrence } \\
\hline Location & RUL, RLL & RLL & RCC, RLL & RML & RUL \\
\hline Size $(\mathrm{cm})$ & 1,2 & 3.5 & $5,0.5$ & 3 & 1 \\
\hline Resection & Wedge & Lobectomy & Rib resection, Lobectomy & Wedge & Wedge \\
\hline Tumor differentiation grade & Low, low & Low & Low, benign & Low & Low \\
\hline Postresection treatment & No & No & No & No & No \\
\hline Secondary recurrence & No & Yes & No & No & No \\
\hline Location & - & Left adrenal gland & - & - & - \\
\hline Size $(\mathrm{cm})$ & - & 3 & - & - & - \\
\hline Resection & - & Laparoscope & - & - & - \\
\hline Tumor differentiation grade & - & Low & - & - & - \\
\hline Postresection treatment & - & No & - & - & - \\
\hline Alive & Yes & Yes & Yes & Yes & Yes \\
\hline \multicolumn{6}{|l|}{ Time from transplant (mo) } \\
\hline to thoracic recurrence & 32 & 33 & 12 & 8 & 11 \\
\hline to secondary recurrence & - & 39 & - & - & - \\
\hline Survival time from TRR (mo) & 53 & 16 & 8 & 9 & 3 \\
\hline
\end{tabular}

$R U L$, Right upper lobe; $R L L$, right lower lobe; $R C C$, right costal cartilage; $R M L$, right middle lobe; $T R R$, thoracic recurrence resection.

\section{References}

1. Okuda K, Ohtsuki T, Obata H, et al. Natural history of hepatocellular carcinoma and prognosis in relation to treatment: study of 850 patients. Cancer. 1985;56: 918-28.
2. Si MS, Amersi F, Golish SR. Prevalence of metastases in hepatocellular carcinoma: risk factors and impact on survival. Am Surg. 2003;69:879-85.

3. Bates MJ, Farkas E, Taylor D, McFadden PM. Pulmonary resection of metastatic hepatocellular carcinoma after liver transplantation. Ann Thorac Surg. 2008;85:412-5.

\section{Radio-guided surgery for ventricular remodeling in patients with ischemic dilated cardiomyopathy: A new tool to discriminate in vivo viable myocardium and scar}

Marco Spadafora, MD, ${ }^{\mathrm{a}, \mathrm{d}}$ Fiore Manganelli, MD, ${ }^{\mathrm{b}}$ Luigi Mansi, MD, ${ }^{\mathrm{c}, \mathrm{d}}$ Paolo Ferrara, MD, ${ }^{\mathrm{b}}$ Paolo Miletto, MD, ${ }^{\mathrm{a}}$ Giuseppe Rosato, MD, ${ }^{\mathrm{b}}$ Pierluigi Costanzo, MD, ${ }^{\mathrm{e}}$ and Alberto Cuocolo, MD, ${ }^{\mathrm{e}, \mathrm{f}}$ Avellino and Naples, Italy

Acombined surgical procedure, left ventricular restoration (LVR), which consists of coronary artery bypass grafting and endoventricular patch plasty (EPP), is under investiga-

\footnotetext{
From the Departments of Imaging ${ }^{\mathrm{a}}$ and Cardiology and Heart Surgery, ${ }^{\mathrm{b}}$ S.G. Moscati Hospital, Avellino, Italy, the Department of Imaging ${ }^{c}$ and the Centre of Excellence in Cardiology, ${ }^{\mathrm{d}}$ Second University of Naples, Naples, Italy; and the SDN Foundation, Institute of Diagnostic and Nuclear Development, ${ }^{\mathrm{e}}$ and the Department of Biomorphological and Functional Sciences, ${ }^{\text {f }}$ University Federico II, Naples, Italy.

Received for publication May 13, 2008; revisions received May 29, 2008; accepted for publication June 7, 2008.

Address for reprints: Marco Spadafora, MD, Department of Imaging, S.G. Moscati

Hospital, Via Otranto, 83100 Avellino, Italy (E-mail: spamar@libero.it).

J Thorac Cardiovasc Surg 2009;138:241-3

0022-5223/\$36.00

Copyright (C) 2009 by The American Association for Thoracic Surgery

doi:10.1016/j.jtcvs.2008.06.017
}

tion in the on-going Surgical Treatment for Ischemic Heart Failure trial. ${ }^{1}$ EPP can provide restoration of left ventricular (LV) size and geometry by excluding nonviable areas. At present, the differentiation of viable tissue and scar tissue is based on using subjective methods to assess morphologic features, such as consistency, thickness, and color of the wall, and it might be inadequate on the surgical table. We assessed the feasibility of in vivo radio-guided surgery (RGS) with a gamma probe as an objective tool to differentiate viable tissue and scar tissue in patients undergoing EPP.

\section{CLINICAL SUMMARY}

Two patients with previous anterior myocardial infarctions were selected for LVR (Table 1). Informed consent 